Available online at www.eccomasproceedia.org

Eccomas Proceedia COMPDYN (2021) 4729-4741

ECCOMAS

Proceedia
COMPDYN 2021

$8^{\text {th }}$ ECCOMAS Thematic Conference on Computational Methods in Structural Dynamics and Earthquake Engineering

M. Papadrakakis, M. Fragiadakis (eds.)

\title{
NUMERICAL MODELLING OF SHEAR BOND TESTS ON EXTERNALLY STRENGTHENED MASONRY SPECIMENS
}

\author{
Ottavio Tamborrino ${ }^{1}$, Daniele Perrone ${ }^{1,2}$ and Marianovella Leone ${ }^{1}$ \\ ${ }^{1}$ University of Salento, Department of Engineering for Innovation, Lecce, Italy \\ Via per Monteroni, Campus Ecotekne, 73047, Monteroni di Lecce LE \\ \{ottavio.tamborrino,daniele.perrone,marianovella.leone\}@unisalento.it \\ ${ }^{2}$ University School for Advanced Studies IUSS Pavia, Pavia, Italy \\ Palazzo del Broletto n16, Piazza della Vittoria, 27100, Pavia \\ daniele.perrone@iusspavia.it
}

\begin{abstract}
Masonry existing structures are prone to significant structural damages when subjected to seismic actions. Over the last decades, innovative techniques emerged as attractive solutions for repair and retrofit of structures. In particular, composite materials with inorganic matrix (FRCMs-CRMs) have emerged as an alternative to fiber reinforced polymers for their better compatibility with masonry substrates. The effectiveness of the strengthening relies on the FRCM-substrate bond behavior, which needs to be characterized for the design of the reinforcement elements. Shear bond tests are able to determine the stress-slip law and the failure mode that rules the FRCM-substrate stress transfer capacity. In the last years, several experimental investigations on shear bond tests of strengthened masonry prisms were performed even if the knowledge about the influence of each variable parameter is not fully known. In this context, the numerical simulation may be a rapid and economic tool to study the incidence of the most relevant parameters in the bond mechanism.

In this paper, a numerical study aimed at simulating the fiber-mortar bond behavior and at calibrating a shear stress ( $\tau$ )-slip (s) constitutive bond law, is presented. Advanced $2 D \mathrm{nu}$ merical models, able to simulate the most probable failure mode occurring in shear bond tests, have been developed. The results of the numerical simulations have been compared with the experimental results of a large database of tests on FRCM/CRM strengthened masonry prisms. An inverse analysis procedure has been used to fit the experimental bond stress versus slip curves and to predict the failure modes.
\end{abstract}

Keywords: Masonry, FRCM, CRM, Bond, Retrofitting, Finite-element model. 


\section{INTRODUCTION}

The structural deficiencies of existing masonry structures, in case of horizontal loading, are well-known in the literature. Generally, the strengthening of masonry walls is performed by means of retrofitting techniques which also implies the use of organic-based composite materials. In order to follow the code requirements in terms of lateral load capacity, and to guaranty the chemical compatibility between the substrate and the adopted strengthening solution, the use of the Fabric Reinforced Cementitious Matrix (FRCM) or Composite Reinforced Mor$\operatorname{tar}(\mathrm{CRM})$ is nowadays considered a suitable solution.

In a large number of structural applications, including the strengthening of masonry walls, the effectiveness of the strengthening is strongly related on the FRCM-substrate bond behavior, which needs to be characterized for the design of the reinforcement and for the assessment of the retrofitted structural members. Experimental investigations have shown that, differently from FRPs, the FRCM-substrate bond failure may take place both within the substrate and within the thickness of the composite. The FRCM-substrate load transfer mechanism may be affected by the textile architecture, the coating or pre-impregnation of the fibers, the mechanical properties and the thickness of the matrix, the mechanical properties of the substrate, as well as by the quality of the application and the curing conditions [1].

In this paper, advanced finite-element 2D models, simulating the failure modes occurred in single-lap shear bond tests, have been developed. The results of the numerical simulations have been compared with the experimental results of a large database of tests on FRCM/CRM strengthened masonry prisms [2-9]. In particular, the database has been divided into two parts: the first one has been used to calibrate a $\tau$-s fiber-mortar law, while the second one to validate the proposed $\tau$-s fiber-mortar law. An inverse analysis procedure has been used to fit the experimental curve and to obtain the actual failure modes. Both a quantitative and a qualitative method have been used to evaluate the goodness of the fitting. Finally, the influence of some important parameters, such as bond length, grid spacing and grid coating on the shear stressslip law results has been discussed.

\section{A DATABASE OF SINGLE-LAP SHEAR BOND TESTS}

In the last years, several experimental investigations on shear bond tests of strengthened masonry specimens were performed. A database collecting the results of the main studies available in the literature involving single-lap shear bond tests has been taken into account aiming to collect all the data required for the numerical simulations. In particular, eight different experimental campaigns were analyzed in the database [2-9].

A single-lap shear bond test allows to characterize the FRCM/CRM-substrate bond behavior by providing the following main information: (i) the peak axial stress $\left(f_{b}\right)$, referred to the cross-sectional area of the longitudinal fibers of the textile $\left(\mathrm{A}_{\mathrm{f}}\right)$; (ii) the axial stress (f) - slip $\left(\mathrm{s}^{*}\right)$ relationship (Fig. 1a), the slip $\mathrm{s}^{*}$ being the relative displacement between the substrate and the textile at the loaded end of the bonded area; and (iii) the failure mode that controls the FRCM-substrate load transfer capacity. Analyzing the data available in the literature, six failure modes can be observed (Fig. 1b):

(a) Debonding with cohesive failure of the substrate;

(b) Debonding at the matrix-substrate interface;

(c) Debonding at the textile-matrix interface;

(d) Textile slippage within the mortar matrix;

(e) Textile slippage within the matrix with cracking of the outer layer of mortar;

(f) Tensile rupture of the textile (out of the bonded area) [1]. 
As reported in Figure 1a, the FRCM-substrate response generally exhibits an initial linear phase, followed by a nonlinear phase up to the attainment of the peak stress value, and a postpeak phase in which the increase of slip is associated to a decrease of the stress.

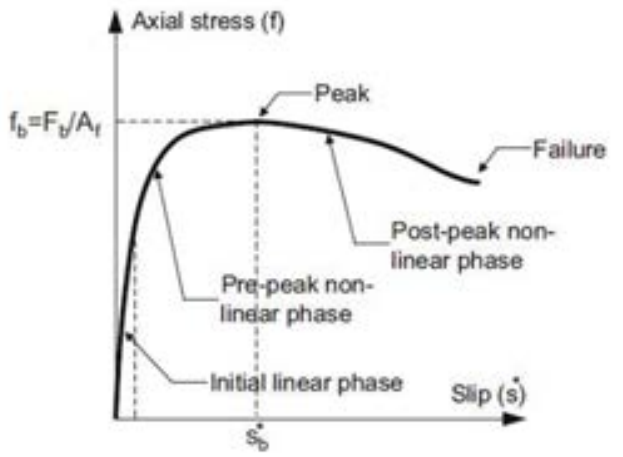

a)

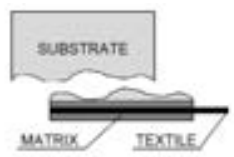

(a)

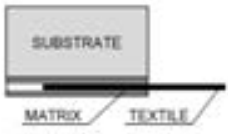

(d)

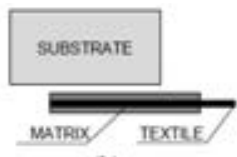

(b)

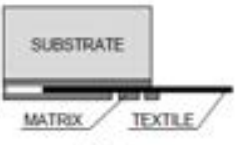

(e)

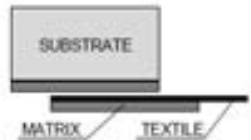

(c)

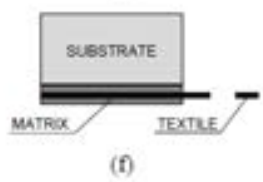

b)

Figure 1: a) axial stress-slip law, b) failure modes [1].

Figure 2 reports both the typical specimen and set-up of a single-lap shear bond test. The grip system is designed "ad hoc" and it is constituted by a steel frame. The tensile force is applied at the specimens through the fabric strengthened at the end. During the tests, the slip between substrate and fiber grid and the slip between substrate and mortar matrix can be recorded [2].

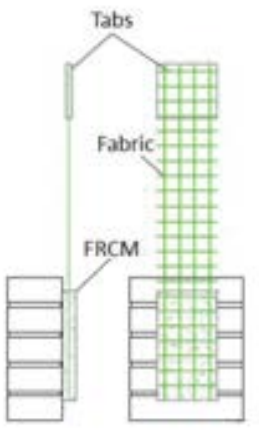

a)

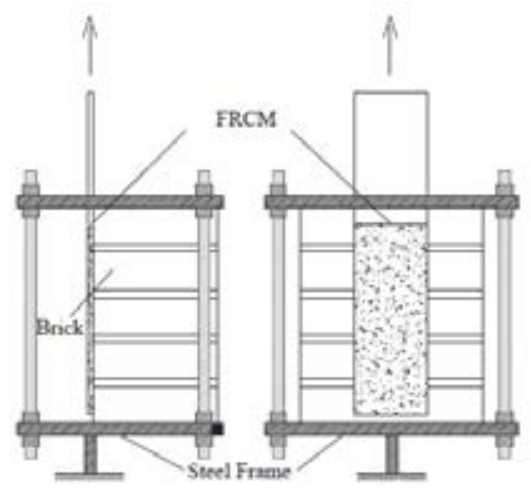

b)

Figure 2: Single lap shear test - a) specimen, b) set-up [2].

Tables 1 and 2 report all the properties of the specimens taken into account to create the database. In particular, Table 1 reports the characteristics of the considered FRCM specimens, while Table 2 reports the properties of the analyzed CRM specimens.

In Lignola et al. [3] the experimental results of bond test between basalt FRCM and masonry, showed that, when the fiber failure is observed, the bond peak stress is similar to the tensile peak stress of the fiber grid; while, when other failure modes occur, the bond peak stress is smaller than the tensile peak stress of the fiber grid. Carozzi et al. [4] observed different failure modes testing carbon FRCM bonded on masonry, the most common being the slippage of the textile within the matrix and the rupture of the textile. Specimens' geometry and curing time of the mortar largely affected the results. The bond tests between glass FRCM and masonry discussed in Bilotta et al. [5] did not underline relevant influence of the mechanical properties of the masonry substrate for the specimens bonded with 1 or 2 grid layers; while this influence is evident for the specimens bonded with 4 grid layers, where the debond- 
ing of the reinforcement from the substrate occurred. Leone et al. [6] observed different failure modes performing single face shear test between glass FRCM and masonry: the most common type was the mortar cracking and tensile failure of glass fiber while cohesive failure of the reinforcement from the substrate never occurred. In D'Antino et al. [7] the failure mode of debonding of the PBO fibers at the matrix-fiber interface always occurred except for four specimens where the detachment of the entire composite from the concrete substrate was observed due to the lack of a surface preparation. The experimental results provided by Carloni et al. [8] on concrete specimens reinforced with PBO FRCM indicated that the values of bond peak load are influenced by the adopted test rate of the slip s ${ }^{*}$. In detail, considering $1 \mathrm{~V}=$ $0.00084 \mathrm{~mm} / \mathrm{s}$, the peak load increases as the rate increases from $0.5 \mathrm{~V}$ to $3 \mathrm{~V}$; the maximum peak load is achieved for a rate between $3 \mathrm{~V}$ and $5 \mathrm{~V}$; while for rate $5 \mathrm{~V}$ or greater, it decreases with increasing rate.

Regarding the CRM reinforcement system, Rizzo [2] and Gattesco et al. [9] investigated the bond behavior between glass CRM and clay masonry substrates. In both studies three different bond lengths were considered: 120, 180 and $240 \mathrm{~mm}$. In [2], for each bond length, the failure occurred by tensile rupture of fibers and the mortar layer was undamaged. In [9], caused by the poorer mechanical properties of the mortar, the failure for longitudinal wires rupture was obtained only for $240 \mathrm{~mm}$, while in the other cases, textile slippage within the matrix with cracking of mortar occurred.

For each experimental campaign, the following information are recorded in the database (Tables 1-2) according to the following labels:

- $\quad$ ID = specimen name;

- $\quad \mathrm{N}=$ number of specimens;

- $\mathrm{ft}_{\mathrm{f}}=$ fiber tensile strength, [MPa];

- $\quad \mathrm{E}_{\mathrm{f}}=$ fiber elastic modulus, [GPa];

- $\quad \mathrm{fc}_{\mathrm{m}}=$ mortar compressive strength, $[\mathrm{MPa}]$;

- $\quad \mathrm{ft}_{\mathrm{m}}=$ mortar tensile strength, [MPa];

- $\mathrm{E}_{\mathrm{m}}=$ mortar elastic modulus, [GPa];

- $\quad \mathrm{t}_{\mathrm{f}}=$ fiber equivalent thickness, $[\mathrm{mm}]$;

- $\quad \mathrm{L}_{\mathrm{ad}}=$ mortar bond length, [mm];

- $\quad b_{a d}=$ mortar width, [mm];

- $\quad \mathrm{t}_{\mathrm{m}}=$ mortar thickness, [mm].

\begin{tabular}{llllllllllll}
\hline ID & $\mathrm{N}$ & $\mathrm{ft}_{\mathrm{f}}$ & $\mathrm{E}_{\mathrm{f}}$ & $\mathrm{fc}_{\mathrm{m}}$ & $\mathrm{ft}_{\mathrm{m}}$ & $\mathrm{E}_{\mathrm{m}}$ & $\mathrm{t}_{\mathrm{f}}$ & $\mathrm{L}_{\mathrm{ad}}$ & $\mathrm{b}_{\mathrm{ad}}$ & $\mathrm{t}_{\mathrm{m}}$ & $\begin{array}{l}\text { Failure } \\
\text { mode }\end{array}$ \\
\hline FRCM4 $^{3}$ & 5 & 871 & 50 & 15 & 1.5 & 8 & 0.023 & 260 & 80 & 10 & $\mathrm{~F}$ \\
FRCM4 $^{3}$ & 5 & 871 & 50 & 15 & 1.5 & 8 & 0.039 & 260 & 100 & 10 & $\mathrm{~F}$ \\
FRCM3 $^{3}$ & 5 & 1201 & 75 & 15 & 1.5 & 6 & 0.058 & 260 & 75 & 10 & $\mathrm{E}$ \\
FRCM2 $^{3}$ & 5 & 2169 & 112 & 12 & 1.2 & 10 & 0.033 & 260 & 75 & 10 & $\mathrm{~F}$ \\
CFRCM4 $^{4}$ & 5 & 1944 & 203 & 20 & 2.0 & 7 & 0.047 & 260 & 100 & 10 & $\mathrm{~F}-\mathrm{D}$ \\
CFRCM4 $^{4}$ & 5 & 1944 & 197 & 20 & 2.0 & 7 & 0.047 & 260 & 50 & 10 & $\mathrm{~F}-\mathrm{D}$ \\
CFRCM5 $^{4}$ & 5 & 2500 & 230 & 38 & 4.3 & 16 & 0.061 & 260 & 100 & 10 & $\mathrm{~F}$ \\
CFRCM6 $^{4}$ & 5 & 1876 & 187 & 16 & 2.8 & 15 & 0.047 & 260 & 50 & 10 & $\mathrm{~F}$ \\
CFRCM6 $^{4}$ & 5 & 1876 & 219 & 16 & 2.8 & 15 & 0.047 & 260 & 60 & 10 & $\mathrm{D}$ \\
G1LMX2 $^{5}$ & 2 & 1275 & 72 & 12 & 2.5 & 8 & 0.035 & 300 & 120 & 10 & $\mathrm{~F}$ \\
G2LMX2 $^{5}$ & 2 & 1275 & 72 & 12 & 2.5 & 8 & 0.070 & 300 & 120 & 10 & $\mathrm{~F}$ \\
F_unipd $^{6}$ & 5 & 1600 & 80 & 15 & 2.7 & 9 & 0.031 & 260 & 40 & 10 & $\mathrm{~F}$ \\
G_polimi $^{6}$ & 5 & 1170 & 72 & 22 & 3.3 & 7 & 0.144 & 260 & 100 & 10 & $\mathrm{E}$ \\
\hline
\end{tabular}




\begin{tabular}{llllllllllll}
\hline G_zag $^{6}$ & 5 & 1170 & 72 & 22 & 3.3 & 7 & 0.144 & 260 & 100 & 10 & $\mathrm{~F}$ \\
H_unina $^{6}$ & 3 & 1275 & 72 & 15 & 2.7 & 8 & 0.035 & 260 & 100 & 10 & $\mathrm{~F}$ \\
DS_60U & 5 & 3014 & 206 & 28 & 3.5 & 6 & 0.092 & 450 & 60 & 8 & $\mathrm{C}$ \\
DS_80U $^{7}$ & 5 & 3014 & 206 & 28 & 3.5 & 6 & 0.092 & 450 & 80 & 8 & $\mathrm{C}$ \\
DS_80V $^{8}$ & 4 & 3014 & 206 & 23 & 4.8 & 6 & 0.092 & 450 & 80 & 8 & $\mathrm{C}$ \\
\hline
\end{tabular}

Table 1: Database bond FRCM [3-8].

\begin{tabular}{llllllllllll}
\hline $\mathrm{ID}$ & $\mathrm{N}$ & $\mathrm{ft}_{\mathrm{f}}$ & $\mathrm{E}_{\mathrm{f}}$ & $\mathrm{fc}_{\mathrm{m}}$ & $\mathrm{ft}_{\mathrm{m}}$ & $\mathrm{E}_{\mathrm{m}}$ & $\mathrm{t}_{\mathrm{f}}$ & $\mathrm{L}_{\mathrm{ad}}$ & $\mathrm{b}_{\mathrm{ad}}$ & $\mathrm{t}_{\mathrm{m}}$ & $\begin{array}{l}\text { Failure } \\
\text { mode }\end{array}$ \\
\hline $\mathrm{G} 66-120^{2}$ & 4 & 1084 & 55 & 25 & 2.5 & 20 & 0.058 & 120 & 132 & 30 & $\mathrm{~F}$ \\
$\mathrm{G} 66-180^{2}$ & 5 & 1084 & 55 & 25 & 2.5 & 20 & 0.058 & 180 & 132 & 30 & $\mathrm{~F}$ \\
$\mathrm{G} 66-240^{2}$ & 3 & 1084 & 55 & 25 & 2.5 & 20 & 0.058 & 240 & 132 & 30 & $\mathrm{~F}$ \\
$\mathrm{G} 33-240^{2}$ & 4 & 1084 & 55 & 25 & 2.5 & 20 & 0.115 & 240 & 132 & 30 & $\mathrm{E}-\mathrm{F}$ \\
$\mathrm{A} 66-1^{9}$ & 4 & 1084 & 55 & 8 & 0.8 & 8 & 0.058 & 120 & 132 & 30 & $\mathrm{E}$ \\
$\mathrm{A} 66-2^{9}$ & 5 & 1084 & 55 & 8 & 0.8 & 8 & 0.058 & 180 & 132 & 30 & $\mathrm{E}$ \\
$\mathrm{A} 66-3^{9}$ & 5 & 1084 & 55 & 8 & 0.8 & 8 & 0.058 & 240 & 132 & 30 & $\mathrm{~F}$ \\
\hline
\end{tabular}

Table 2: Database bond CRM [2, 9].

\section{NUMERICAL MODELLING}

In this study, 2D finite-element models, simulating FRCM/CRM-masonry bond tests, have been developed using Midas FEA [10].

The adopted two-dimensional model, schematized in Figure 3, is able to simulate the main failure modes occurring in a single-lap shear bond test, except for the A and/or B mode that involved the substrate (Fig. 1b). These failure modes were excluded because were not observed in the collected database. This assumption allowed to simply the numerical model because the masonry substrate was not modelled, and it was replaced by fixed boundaries assigned to the mortar. This assumption is also feasible because the masonry prism is constrained to the steel supporting frame of the test set-up (Fig. 2). In detail, the adopted numerical models are similar to that developed in [11], and composed of:

- Mortar (two layers): it is modelled through four-node plane-stress 2D elements (A = $5 \times 5 \mathrm{~mm}^{2}$ ) with a linear elastic behavior. The behavior was characterized using the elastic modulus and tensile strength provided in the experimental campaigns. The thickness is equal to the mortar width;

- $\quad$ Fiber grid: it is modelled through two-node truss 1D elements $(1=5 \mathrm{~mm})$, with a linear elastic behavior. The behavior was characterized using the elastic modulus and tensile strength provided in the experimental campaigns. The cross-sectional area $\left(A_{f}\right)$ is equal to the sum of transversal areas of each yarn;

- $\quad$ Fiber-mortar interface (two layers): it is modelled through line interface zero-thickness elements, characterized from a nonlinear bond-slip $\tau$-s mechanical law. The thickness is equal to the sum of wet perimeters of each yarn;

- Upper-lower mortar interface: it is modelled through point interface zero-thickness elements, characterized from an infinitely rigid behavior.

In this study, a specific cracking modelling of the mortar was not introduced, for this reason is not possible to monitor the cracking development within the mortar. However, it is worth mentioning that this is out of the scope of this work. 
The analyses have been conducted in displacement control using the Newton Raphson convergence method. The horizontal maximum displacement is assigned at the loaded end of the equivalent yarn and divided into 50 incremental steps.

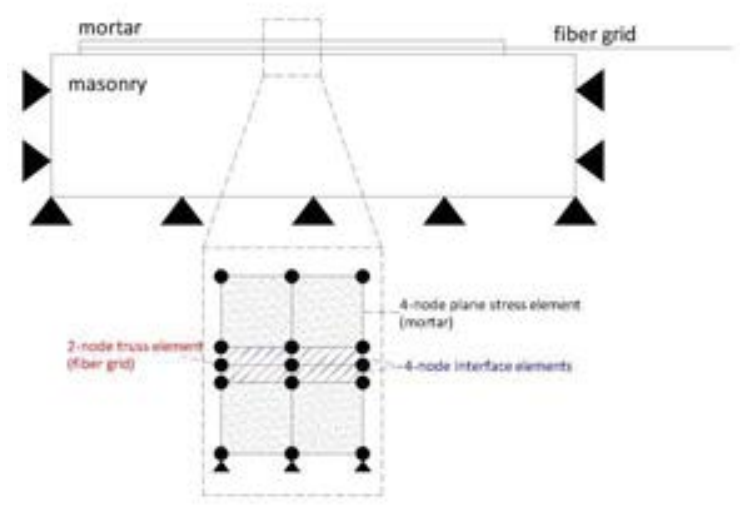

Figure 3: Adopted 2D modelling.

The most critical point in the adopted modelling approach consists in the definition of the nonlinear bond-slip ( $\tau$-s) mechanical law. This law will be calibrated for each specimen available in the database in order to find a correlation between the different involved parameters. As a starting point, the shape of the curve has been defined considering some studies available in the literature. In [12], shear bond tests on SRG systems were simulated introducing a steelmortar nonlinear interface, whose fundamental parameters influence the eventual failure mechanism of the specimen for slippage of the steel cords from the grout.

In particular, with the aim to numerically define this interface, the authors chose a tri-linear constitutive law, taking into account the experimentally observed friction phenomena between textile and matrix (Fig. 4). The same bond stress-slip law form was introduced in [13], where a cohesive interface crack model for the matrix-textile debonding in FRCM composites was developed.

Following a similar approach, in this work, the fundamental values of the adopted bond $\tau$-s law are (Fig. 4): $\tau_{\mathrm{m}}$ (bond strength), $\tau_{\mathrm{r}}$ (residual bond stress), $\mathrm{s}_{0}$ (slip corresponding to $\tau_{\mathrm{m}}$ ), $\mathrm{s}_{1}$ (slip at the end of softening branch) and $\mathrm{s}_{2}$ (ultimate slip). All the parameters have been defined through the calibration of the model using the experimental results. The simplified bond stress-slip law of the interface implies a first linear elastic behavior as the pre-peak branch (until the maximum stress $\tau_{\mathrm{m}}$ ), followed by a linear softening part representing loss of cohesion between the two materials in the interface. The third branch with the constant bond stress of $\tau_{\mathrm{r}}$ represents the frictional resistance of the interface, this branch is only necessary for convergence reasons. 


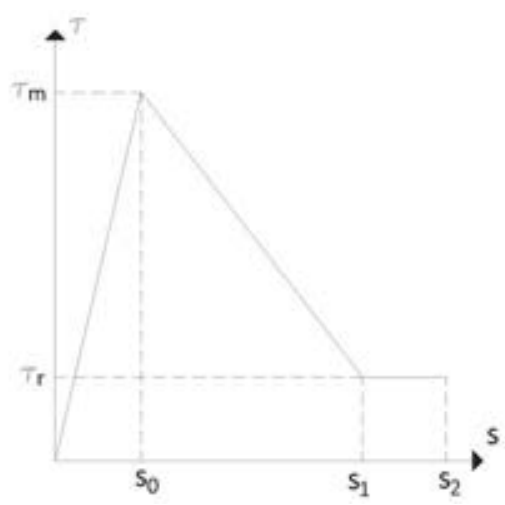

Figure 4: Adopted bond $\tau$-s law.

To demonstrate the effectiveness of the numerical model, a preliminary parametric analysis has been conducted to check the physical robustness of the obtained results. In detail, the ratio between the fiber elastic modulus and the mortar elastic modulus $\left(\mathrm{E}_{\mathrm{f}} / \mathrm{E}_{\mathrm{m}}\right)$ and the interface stiffness $\left(\mathrm{k}_{1}=\tau_{\mathrm{m}} / \mathrm{s}_{0}\right.$ - slope of the bond stress versus slip curves) were varied respect to the ratio between the fiber stress and the mortar stress $\left(\sigma_{\mathrm{f}} / \sigma_{\mathrm{m}}\right)$ at the loaded end.

As expected, $\sigma_{\mathrm{f}} / \sigma_{\mathrm{m}}$ increases as $\mathrm{E}_{\mathrm{f}} / \mathrm{E}_{\mathrm{m}}$ increases (Fig. 5a) while $\sigma_{\mathrm{f}} / \sigma_{\mathrm{m}}$ decreases as $\mathrm{k}_{1}$ increases (Fig. 5b). This last is related to the fact that as increasing $\mathrm{k}_{1}$, the behavior is closer to the perfect bond behavior and the stresses in the two materials are similar.

Furthermore, with the same purpose to check the robustness of the model, the trend of shear bond stress $\tau$ in the fiber-mortar interface, along the specimen, respectively for the case of mortar cracking and interface debonding, has been monitored (Fig. 6). The numerical analyses have showed that, if the crisis affects the mortar, the bond stress level in the interface is such that $\tau$ falls in the first linear elastic phase of the $\tau$-s curve (Fig. 4 ); while when the interface debonding occurs, $\tau$ falls in the second linear softening phase of the $\tau$-s curve. So, it is noticeable that the bond stress trend is opposite between these two cases: in case of mortar cracking, $\tau$ decreases from loaded end (with higher value of slip) to free end (with lower value of slip); in case of interface debonding $\tau$ increases from loaded end to free end.

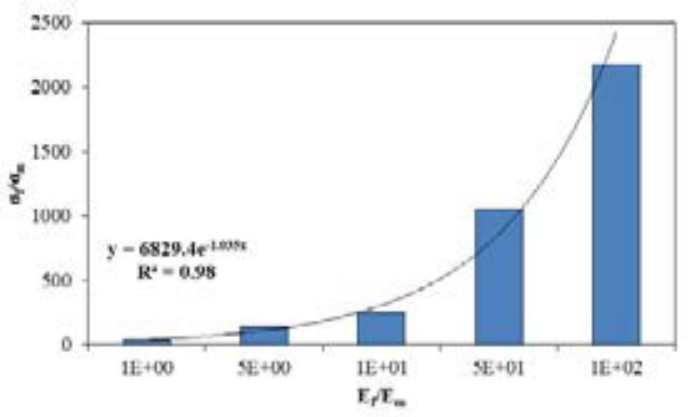

a)

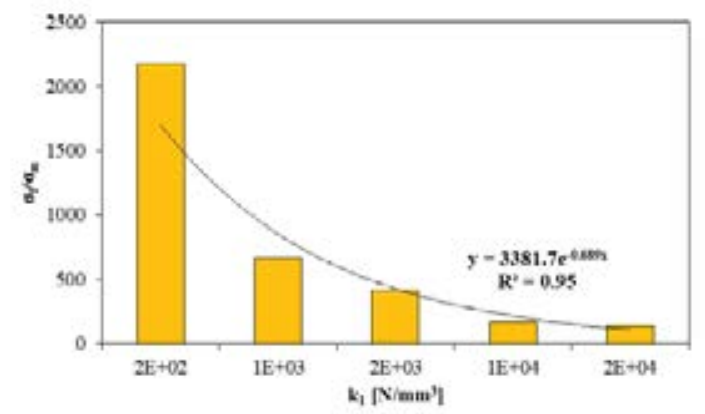

b)

Figure 5: Validation of the numerical model - a) $\left.\sigma_{\mathrm{f}} / \sigma_{\mathrm{m}} \mathrm{vs} \mathrm{E}_{\mathrm{f}} / \mathrm{E}_{\mathrm{m}}, \mathrm{b}\right) \sigma_{\mathrm{f}} / \sigma_{\mathrm{m}} \mathrm{vs} \mathrm{k}_{1}$. 


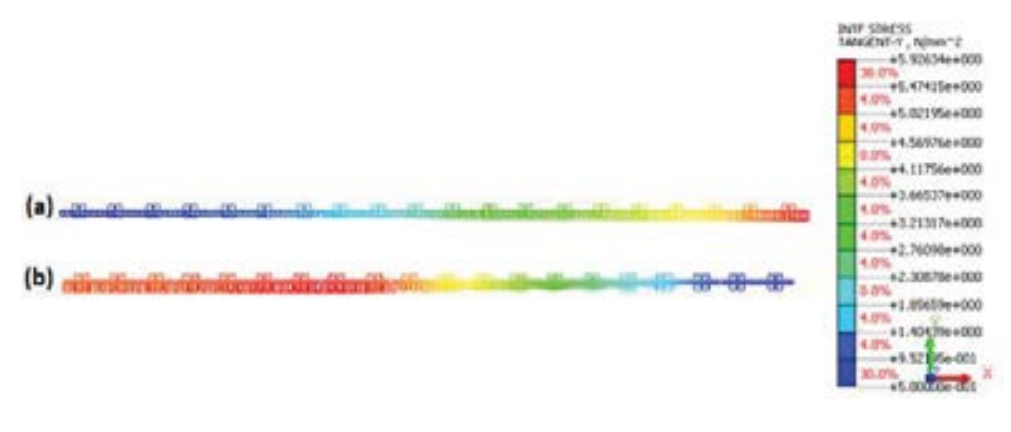

Figure 6: Interface stress mapping - mortar (a) and interface (b) failure.

\section{CALIBRATION OF BOND-SLIP INTERFACE LAW}

The finite-element model described in Section 3 has been developed to simulate all the results collected in the FRCM/CRM-masonry single-lap shear bond tests database presented in Section 2. The database has been divided into two homogeneous parts: i) the first part has been used to calibrate the fiber-mortar interface laws ( $76 \%$ of the specimens); ii) the second part has been used for validation purpose ( $24 \%$ of the specimens).

The percentage assigned to the calibration and validation part was selected referring to similar studies available in the literature [14].

For each specimen, an inverse analysis has been made, looking for the best fitting between the experimental and numerical axial stress (f) - slip ( $\mathrm{s}^{*}$ ) curve to obtain the fiber-mortar $\tau$-s interface law. For example, in Figure 7 and Figure 8, the experimental-numerical best fitting with the corresponding $\tau$-s output related to the FRCM specimen "FRCM2-01" (Tab. 1) and to the CRM specimen "G66-120-01" (Tab. 2), respectively, are reported.

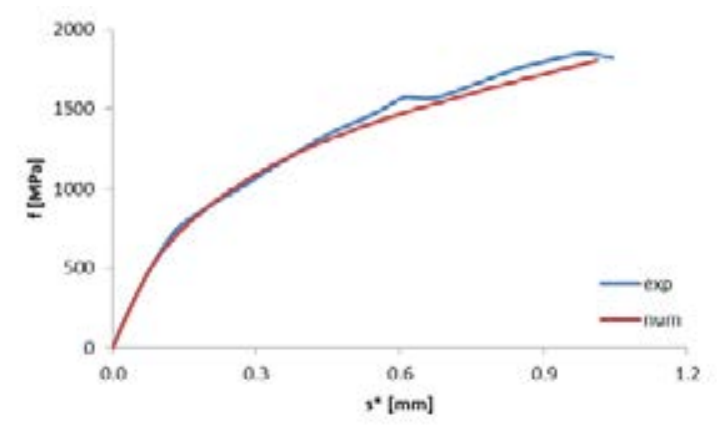

a)

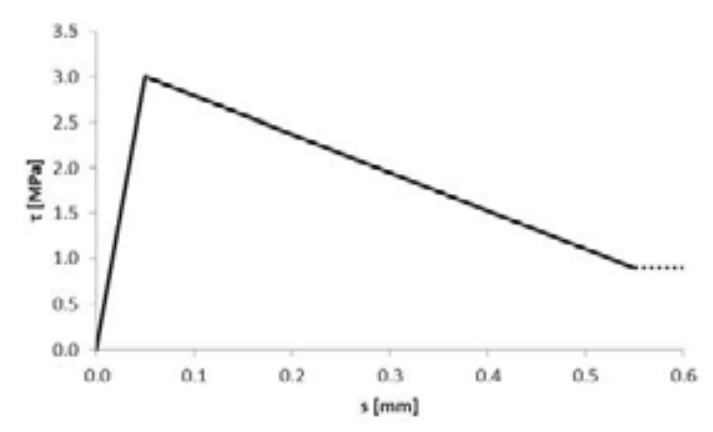

b)

Figure 7: FRCM specimen - a) experimental-numerical best fitting, b) bond interface law.

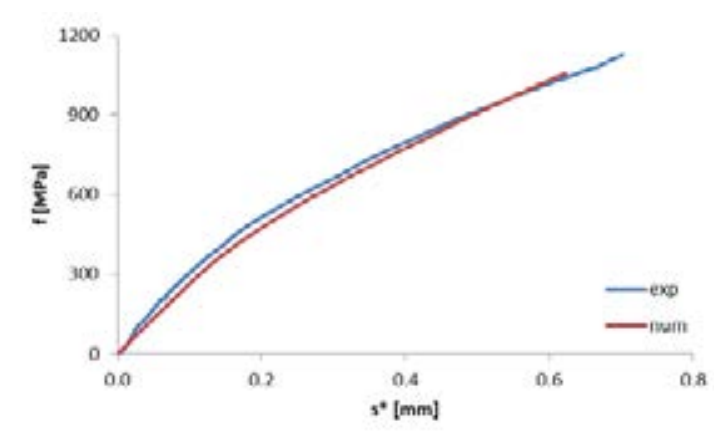

a)

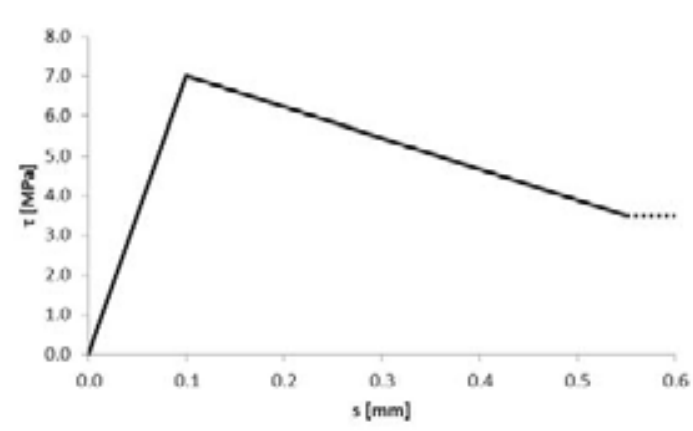

b)

Figure 8: CRM specimen - a) experimental-numerical best fitting, b) bond interface law. 
For each inverse analysis, the goodness of the experimental-numerical fitting has been assessed through both qualitative and quantitative methods. The quantitative control has been made comparing the experimental and numerical peak axial stress ( $\left.f_{b} e x p, f_{b} n u m\right)$ and corresponding slip ( ${ }^{*}{ }_{b}$ exp, ${ }^{*}{ }_{b}$ num).

In Figure 9, each doth represent a different specimen. It can be observed that the correlation in terms of stress is better than slip; in fact, the average value of $f_{b}$ exp/ $f_{b}$ num is equal to $1.00(\mathrm{COV}=7.4 \%)$, while the average value of $\mathrm{s}_{\mathrm{b}}{ }_{\mathrm{b}} \mathrm{exp} / \mathrm{s}_{\mathrm{b}}{ }_{\mathrm{b}}$ num is equal to $1.13(\mathrm{COV}=27.8 \%)$.

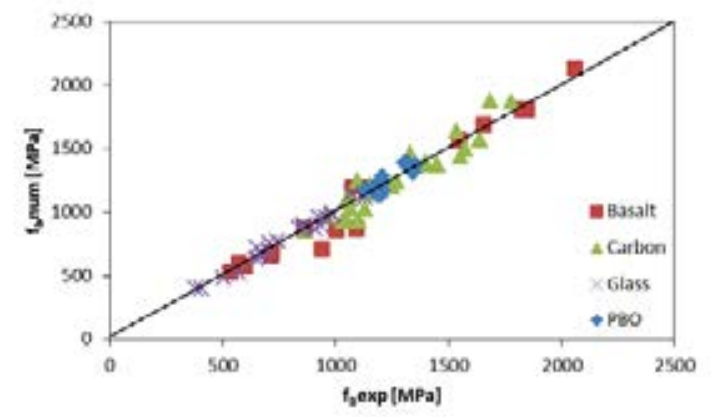

a)

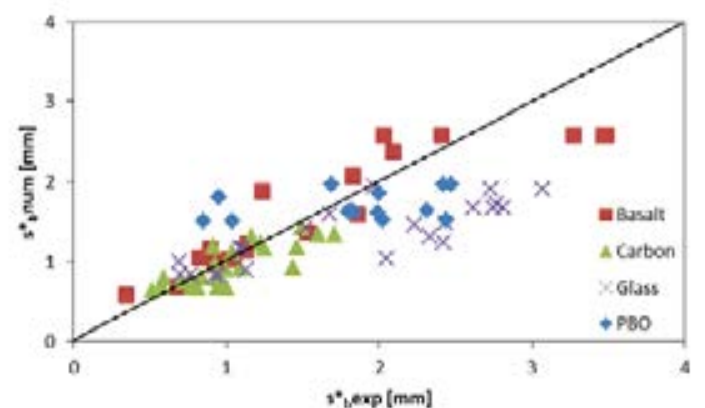

b)

Figure 9: a) experimental-numerical dispersion for $f_{b}, b$ ) experimental-numerical dispersion for $\mathrm{s}_{\mathrm{b}}$.

In Figure 10 the comparisons between average $\tau$-s curves varying $\mathrm{E}_{\mathrm{f}}{ }^{*} \mathrm{t}_{\mathrm{f}}[\mathrm{kN} / \mathrm{mm}]$ and $\mathrm{ft}_{\mathrm{m}}$ $[\mathrm{MPa}]$, only related to FRCM specimens, are reported. A correlation between the stiffness of the reinforcement and the interface behavior is not completely clear as well as a trend between the tensile strength of the mortar and the peak of the bond-slip curve cannot be defined. Probably other parameters (for example grid coating and spacing), that have been neglected, might affect the obtained results.

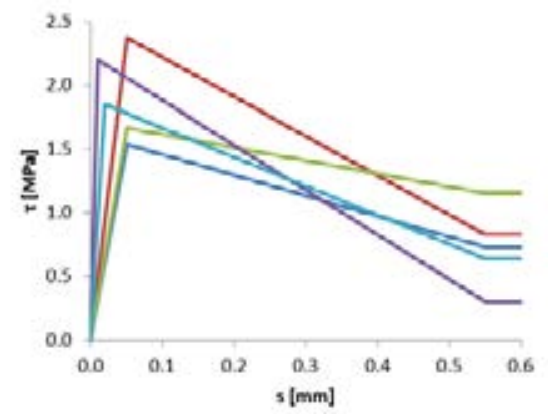

a)

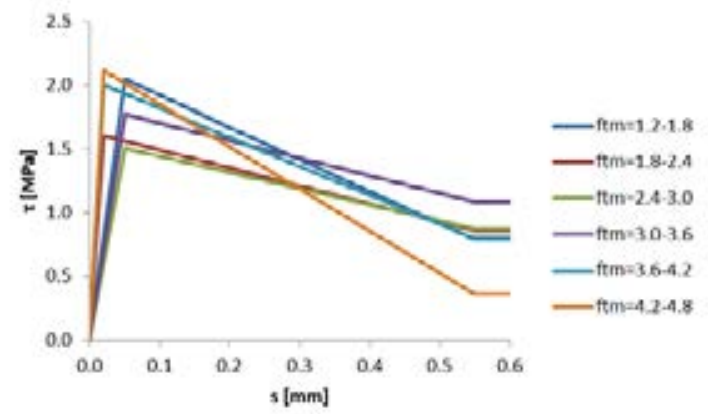

b)

Figure 10: $\tau$-s average curves varying a) $\mathrm{E}_{\mathrm{f}} * \mathrm{t}_{\mathrm{f}}$ and $\mathrm{b}$ ) $\mathrm{ft}_{\mathrm{m}}$.

\subsection{Discussion}

In order to investigate the influence of other parameters that could affect the interface behavior, the superficial grid coating and the grid spacing $\left(\mathrm{s}_{\mathrm{f}}\right)$ have been analyzed. In particular, the incidence of these two parameters on the bond law has been investigated considering two representative specimen groups, extracted from the FRCM database (Tab. 1), composed of specimens characterized by similar properties in terms of mortar and fibers:

- Group $1\left(\mathrm{E}_{\mathrm{f}}=50-80 \mathrm{GPa}, \mathrm{fc}_{\mathrm{m}}=12-17 \mathrm{MPa}\right)$, composed of 13 specimens;

- Group $2\left(\mathrm{E}_{\mathrm{f}}=80-110 \mathrm{GPa}, \mathrm{fc}_{\mathrm{m}}=12-17 \mathrm{MPa}\right)$, composed of 10 specimens.

Each of these two groups is divided into two parts: 
- Part a), characterized by a higher spaced grid $\left(\mathrm{s}_{\mathrm{f}}=25 \mathrm{~mm}\right)$;

- Part b), characterized by a lower spaced grid $\left(\mathrm{s}_{\mathrm{f}}=10 \mathrm{~mm}\right)$.

In Figure 11, the blue and the red columns indicates the average value of $\tau_{\mathrm{m}}$ (Fig. 11a) and $\mathrm{k}_{1}$ (Fig. 11b), respectively, for the part a) and the part b) of each group. It is expected that the presence of more transversal wires, in case of lower spaced grids, should cause a more significant increment of $\tau_{\mathrm{m}}$ and $\mathrm{k}_{1}$ than in higher spaced grids [2]. However, in the analyzed case, as evidenced in Figure 11, this trend is confirmed only for the Group 1 and it's completely opposite for the Group 2.

In fact, while all the specimens belonging to the Group 1 are characterized by the presence of a superficial grid coating; in the Group 2, only the specimens with higher spaced grids are characterized by the coating. So, this opposite trend could be justified by the fact that the presence (or absence) of the coating could have a greater influence than the grid spacing.

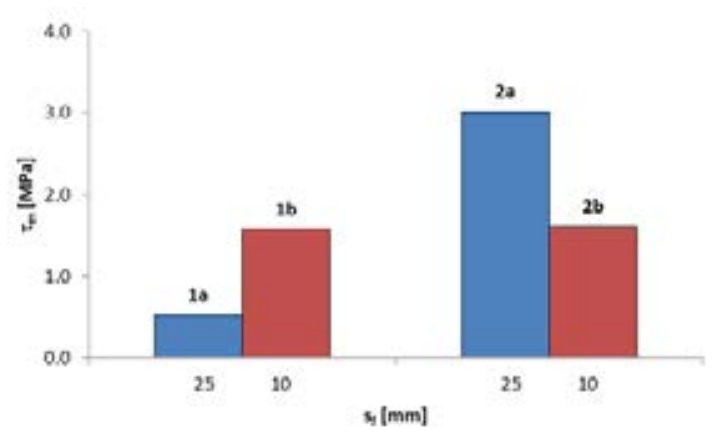

a)

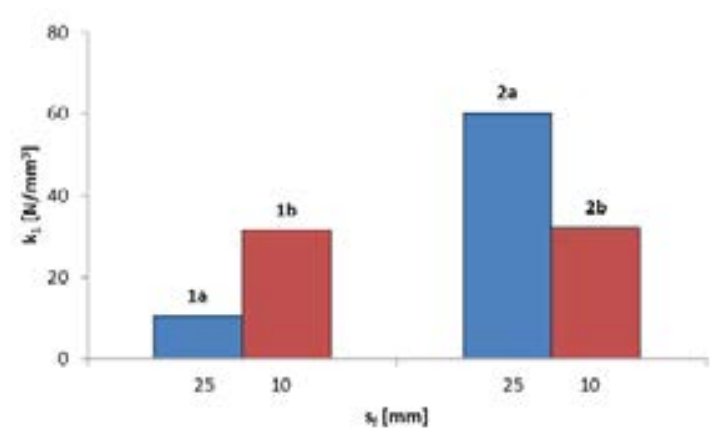

b)

Figure 11: Grid coating and spacing effect in terms of: a) $\tau_{\mathrm{m}}$ and b) $\mathrm{k}_{1}$.

The campaign on shear bond tests between GCRM and masonry, conducted by Rizzo [2] (explained in Section 2), was also used to individuate the effective bond length ( $\mathrm{L}_{\mathrm{eff}}$ ), beyond which there are no more significant increases in terms of peak axial stress $f_{b}$. The authors observed that $\mathrm{f}_{\mathrm{b}}$ seems to be growing up from $120 \mathrm{~mm}$ until $180 \mathrm{~mm}$, after that it remains almost constant at $240 \mathrm{~mm}$. So, the effective bonded length could be estimated equal to $180 \mathrm{~mm}$. From the numerical simulation of these bond tests, the same value of $\mathrm{L}_{\text {eff }}$ has been obtained (Fig. 12).

This analysis, with the aim to evaluate an effective bond length, has been extended to FRCM-masonry specimens with different mechanical properties. In detail, the numerical analysis has been made varying the mortar tensile strength $\mathrm{ft}_{\mathrm{m}}$ (from 0.10 to $2.00 \mathrm{MPa}$ ) and the bond length $\mathrm{L}_{\mathrm{ad}}$ (from 20 to $300 \mathrm{~mm}$ ); while the grid properties have been kept constant: $\mathrm{E}_{\mathrm{f}}=300 \mathrm{GPa}$ and $\mathrm{ft}_{\mathrm{f}}=3000 \mathrm{MPa}$.

Figure 13 reports the variation of $\mathrm{f}_{\mathrm{b}}$ as a function of $\mathrm{ft}_{\mathrm{m}}$ (Fig. 13a) and $\mathrm{L}_{\mathrm{ad}}$ (Fig. 13b). In Figure 13a, the constant branch of each curve begins when the failure mode changes from mortar cracking to interface debonding without more increments in terms of $\mathrm{f}_{\mathrm{b}}$. It is noticeable that increasing the bond length the mode of failure changes for low value of the mortar tensile strength.

From Figure $13 b$, it is evident that for lower values of $\mathrm{ft}_{\mathrm{m}}, \mathrm{f}_{\mathrm{b}}$ increases as $\mathrm{L}_{\mathrm{ad}}$ increases; however, for mortar tensile strength greater than $1.00 \mathrm{MPa}$ and for $\mathrm{L}_{\mathrm{ad}}$ values greater than 150 $\mathrm{mm}$, the slope of the curve rapidly decreases and there are no more important increments in terms of $\mathrm{f}_{\mathrm{b}}$. In conclusion, $\mathrm{L}_{\mathrm{ad}}$ equal to $150 \mathrm{~mm}$ seems to be the effective bond length ( $\left.\mathrm{L}_{\mathrm{eff}}\right)$ for specimens characterized by $\mathrm{E}_{\mathrm{f}}=300 \mathrm{GPa}$ and $\mathrm{ft}_{\mathrm{f}}=3000 \mathrm{MPa}$. 


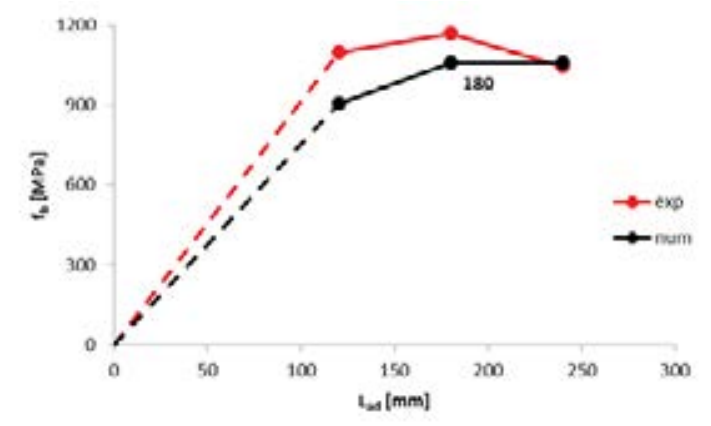

Figure 12: Peak axial stress trend in function of $\mathrm{L}_{\mathrm{ad}}$.

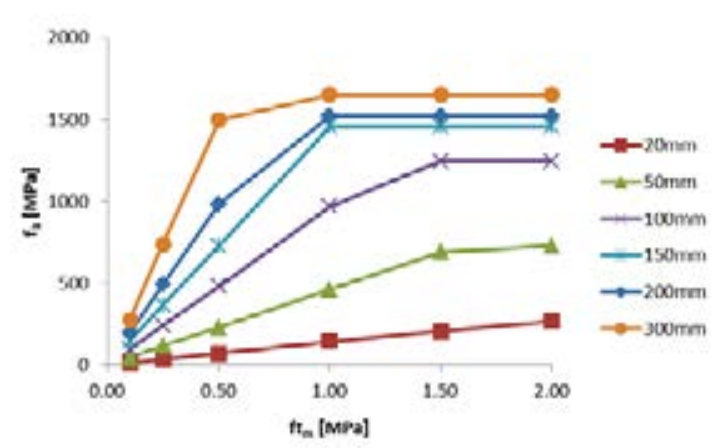

a)

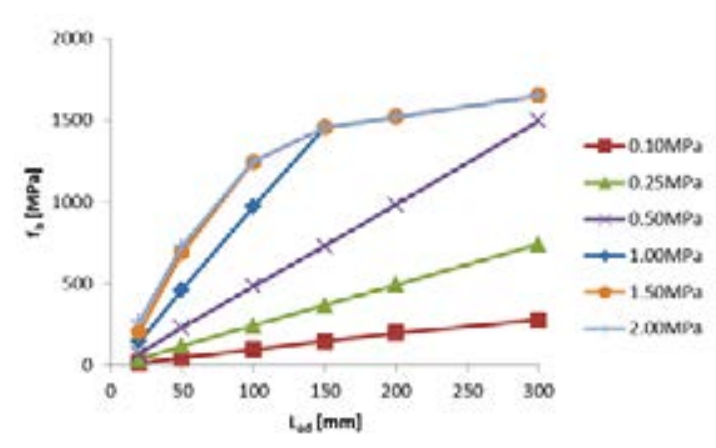

b)

Figure 13: Peak axial stress trend $-\mathrm{a}) \mathrm{ft}_{\mathrm{m}}$ and $\mathrm{b}$ ) $\mathrm{L}_{\mathrm{ad}}$.

\section{CONCLUSIONS}

The effectiveness of the FRCM/CRM strengthening techniques relies on the compositesubstrate bond behavior. In this study, numerical simulations aimed to study the interface behavior have been carried out. The obtained results that represent the first part of a wider study are able to furnish the following conclusions:

- A simplified finite-element 2D model, able to simulate the main failure modes occurring in a single-lap shear bond test between FRCM/CRM and masonry, has been developed.

- An inverse numerical analysis has been used to calibrate the $\tau$-s law between fiber and mortar and to simulate the results of single-lap shear bond tests. The comparison between the numerical and experimental results demonstrated the effectiveness of the proposed numerical modelling approach.

- The influence of some important parameters, such as grid spacing and grid coating on the $\tau$-s law results has been investigated. For the analyzed cases, it has been observed that for masonry reinforced with coated FRCM, lower spaced grids give higher values of both maximum bond stress $\left(\tau_{\mathrm{m}}\right)$ and slope of the bond stress versus slip curves $\left(\mathrm{k}_{1}\right)$.

- The performed numerical analysis seems to be able to estimate the transfer length of the reinforcement.

- At the date, numerical simulations are still in progress with particular reference to shear bond tests between CRM and masonry. In the future, is in the authors' intent to carry out pull-out tests on FRCM and CRM specimens [15] in order to experimentally obtain $\tau$-s fiber-mortar relationships for comparison with the numerically obtained laws. 


\section{ACKNOWLEDGEMENTS}

This study was supported by the ReLUIS-program 2019-2021, PR 5 - “'Materiali innovativi per applicazioni su costruzioni esistenti',

\section{REFERENCES}

[1] De Felice, G., Aiello, M. A., Caggegi, C., Ceroni, F., De Santis, S., Garbin, E., ... \& Viskovic, A. (2018). Recommendation of RILEM Technical Committee 250-CSM: Test method for Textile Reinforced Mortar to substrate bond characterization. Materials and Structures, 51(4), 1-9.

[2] Rizzo, V. (2020). Bond Behaviour and Durability in Alkaline Environments of Composite Strengthening Systems (Doctoral dissertation).

[3] Lignola, G. P., Caggegi, C., Ceroni, F., De Santis, S., Krajewski, P., Lourenço, P. B., ... \& Zuccarino, L. (2017). Performance assessment of basalt FRCM for retrofit applications on masonry. Composites Part B: Engineering, 128, 1-18.

[4] Carozzi, F. G., Bellini, A., D'Antino, T., de Felice, G., Focacci, F., Hojdys, Ł., ... \& Poggi, C. (2017). Experimental investigation of tensile and bond properties of CarbonFRCM composites for strengthening masonry elements. Composites Part B: Engineering, 128, 100-119.

[5] Bilotta, A., Ceroni, F., Nigro, E., \& Pecce, M. (2017). Experimental tests on FRCM strengthening systems for tuff masonry elements. Construction and building Materials, 138, 114-133.

[6] Leone, M., Aiello, M. A., Balsamo, A., Carozzi, F. G., Ceroni, F., Corradi, M., ... \& Saenger, D. (2017). Glass fabric reinforced cementitious matrix: Tensile properties and bond performance on masonry substrate. Composites Part B: Engineering, 127, 196214.

[7] D’Antino, T., Sneed, L. H., Carloni, C., \& Pellegrino, C. (2015). Influence of the substrate characteristics on the bond behavior of PBO FRCM-concrete joints. Construction and Building Materials, 101, 838-850.

[8] Carloni, C., Verre, S., Sneed, L. H., \& Ombres, L. (2017). Loading rate effect on the debonding phenomenon in fiber reinforced cementitious matrix-concrete joints. Composites Part B: Engineering, 108, 301-314.

[9] Gattesco, N., \& Boem, I. (2017). Characterization tests of GFRM coating as a strengthening technique for masonry buildings. Composite Structures, 165, 209-222.

[10] Midas FEA NX Advanced Nonlinear and Detail Analysis System. Copyright (C) Since 1989, MIDAS Information Technology Co., Ltd. All Rights Reserved. http://www.midasuser.com/.

[11] Ghiassi, B., Marcari, G., Oliveira, D. V., \& Lourenço, P. B. (2012). Numerical analysis of bond behavior between masonry bricks and composite materials. Engineering Structures, 43, 210-220.

[12] Razavizadeh, A., Ghiassi, B., \& Oliveira, D. V. (2014). Bond behavior of SRGstrengthened masonry units: Testing and numerical modeling. Construction and Building Materials, 64, 387-397. 
[13] Carozzi, F. G., Colombi, P., Fava, G., \& Poggi, C. (2016). A cohesive interface crack model for the matrix-textile debonding in FRCM composites. Composite Structures, $143,230-241$.

[14] Haddad, R., \& Haddad, M. (2020). Predicting fiber - reinforced polymer - concrete bond strength using artificial neural networks: A comparative analysis study. Structural Concrete.

[15] Barhum, R., \& Mechtcherine, V. (2012). Effect of short, dispersed glass and carbon fibres on the behaviour of textile-reinforced concrete under tensile loading. Engineering Fracture Mechanics, 92, 56-71. 